\title{
Histopathological implications of ventricle wall 5-aminolevulinic acid-induced fluorescence in the absence of tumor involvement on magnetic resonance images
}

\author{
JU HYUNG MOON ${ }^{1}$, SE HOON KIM ${ }^{2}$, JIN-KYOUNG SHIM ${ }^{1}$, TAE-HOON ROH ${ }^{1}$, \\ KYOUNG SU SUNG ${ }^{1}$, JI-HYUN LEE ${ }^{1}$, JUNSEONG PARK ${ }^{1}$, JUNJEONG CHOI ${ }^{3}$, \\ EUI-HYUN KIM ${ }^{1}$, SUN HO KIM ${ }^{1}$, SEOK-GU KANG ${ }^{1}$ and JONG HEE CHANG ${ }^{1}$ \\ Departments of ${ }^{1}$ Neurosurgery and ${ }^{2}$ Pathology, Brain Tumor Center, Severance Hospital, \\ Yonsei University College of Medicine, Seoul; ${ }^{3}$ Department of Pharmacy, College of Pharmacy, \\ Yonsei Institute of Pharmaceutical Sciences, Yonsei University, Incheon, Republic of Korea
}

Received February 9, 2016; Accepted March 28, 2016

DOI: $10.3892 / o r .2016 .4881$

\begin{abstract}
During 5-aminolevulinic acid (ALA)-guided glioblastoma multiforme (GBM) surgery, we encountered fluorescence in ventricular walls that lacked enhancement on magnetic resonance (MR) images and were free of macroscopic invasion of tumor cells. However, the meaning of ventricular wall fluorescence during 5-ALA-guided surgery is still unknown. The aim of this study was to investigate the relationship between intraoperative 5-ALA fluorescence and histopathological findings of ventricular walls free of enhancement on MR images. Nineteen patients with newly diagnosed GBM located near the lateral ventricle underwent 5-ALA fluorescence-guided surgery. During the surgery, the ventricle wall was opened and investigated with the aid of a surgical microscope equipped with optical filters to examine 5-ALA fluorescence of the ventricular wall. Twenty-five ventricular wall tissues that were apparently free of tumor involvement by MR imaging and macroscopic observation were obtained during surgery. Among the 19 cases with brightly fluorescing tumor masses, 11 patients $(57.9 \%)$ exhibited 5-ALA-induced fluorescence in the ventricular wall. Of the 25 ventricular wall samples, 11 exhibited 5-ALA-induced fluorescence; upon pathologic examination, tumors were present in 5 samples $(45.5 \%)$, but the remaining $6(54.5 \%)$ were free of tumor cells. A pathologic examination revealed no tumor cells in the 14 samples that lacked 5-ALA-induced fluorescence. Our data suggest the possibility that glioma cells exhibiting 5-ALA
\end{abstract}

Correspondence to: Professor Seok-Gu Kang, Department of Neurosurgery, Brain Tumor Center, Severance Hospital, Yonsei University College of Medicine, 50-1 Yonsei-ro, Seodaemun-gu, Seoul 120-752, Republic of Korea

E-mail: seokgu9@gmail.com

Key words: 5-aminolevulinic acid, fluorescence, glioblastoma, pathology, ventricular wall fluorescence are present in the ventricle wall, despite no signs of tumor involvement in MR images. Further investigation of non-tumor cells from tissues with 5-ALA fluorescence is needed to understand the nature of this unexpected ventricular wall fluorescence.

\section{Introduction}

5-Aminolevulinic acid (5-ALA) is a natural metabolic precursor in the heme biosynthesis pathway. Oral administration of a large volume of 5-ALA overloads the heme pathway and induces the synthesis and selective accumulation of the fluorescent protoporphyrin IX (PpIX) in tumor cells and epithelial tissue $(1,2)$. Increased vascular permeability attributable to disruption of the blood-brain barrier (BBB) in the tumor and decreased levels of ferrochelatase activity in tumor cells contribute to this phenomenon in glioblastoma multiforme (GBM) (3-6). PpIX in GBM tumors, present at higher levels compared to normal brain tissue, emits red-violet fluorescence under blue light, visually distinguishing tumor margins and allowing intraoperative, objective assessment of tumor infiltration $(7,8)$. Evidence demonstrating the high sensitivity and specificity of 5-ALA-induced PpIX fluorescence in GBM provides support for the diagnostic accuracy of 5-ALA. As a result, 5-ALA fluorescence guidance has come to be widely used to improve the extent of tumor resection (9).

Since a number of studies have demonstrated that the extent of resection (EOR) is correlated with improved prognosis of patients with GBM, neurosurgeons have sought to maximize the EOR, an objective constrained by the difficulties of resection arising from the invasive nature of GBM (10-15). A large, randomized, controlled, multicenter phase III trial has shown that 5-ALA fluorescence-guided surgery for malignant glioma leads to a significantly higher resection rate, resulting in prolonged progression-free survival compared with conventional microsurgery guided by white light (16). In addition, several techniques, including intraoperative neuronavigation (17), intraoperative magnetic resonance (MR) 
imaging (18), intraoperative ultrasound (19) and intraoperative electrical stimulation (20), have been introduced to facilitate optimal resection, thereby maximizing safe EOR and improving survival in patients with GBM. Increasing the EOR of GBM to achieve these survival benefits brings with it a greater chance of entering the ventricular system during the course of cytoreduction. In some cases of 5-ALA-guided GBM surgery, upon ventricular entry we encountered fluorescence in ventricular walls that lacked enhancement on MR images and were free of macroscopic invasion of tumor cells. However, the implications of this 5-ALA-induced fluorescence of the ventricle wall are not yet fully understood.

In this study, we obtained 25 ventricular wall tissues from 19 patients with newly diagnosed GBM that showed no enhancement on MR images, and investigated the relationship between intraoperative 5-ALA fluorescence and histopathology findings of these non-enhancing ventricular wall tissues.

\section{Materials and methods}

Patient information. Nineteen patients who underwent fluorescence-guided surgery with 5-ALA for newly diagnosed GBM at our hospital from December 2012 to May 2015 were included in this study. Approval was given by the Institutional Review Board of Severance Hospital, Yonsei University College of Medicine. Informed consent was provided according to the Declaration of Helsinki. Of these 19 patients, 12 were males and 7 were females, and their age ranged from 45 to 74 years (mean, 58.5 years). All patients were newly diagnosed with GBM, and had no prior history of treatment with surgery, chemotherapy, or radiotherapy. All tumors showed typical enhancement patterns of GBM in MR images after the administration of contrast medium. In all cases, the ventricle was opened during resection of the tumor, which was located near the lateral ventricle. The characteristics of the 19 patients are summarized in Table I.

Surgical procedure. Three hours prior to induction of anesthesia, 5-ALA (Gliolan; Photonamic GmbH \& Co. KG, Wedel, Germany) was administered orally at a dose of $20 \mathrm{mg} / \mathrm{kg}$ body weight. Patients were protected from direct exposure to light sources for $24 \mathrm{~h}$ after intake of 5-ALA to avoid skin phototoxicity. Preoperative, high-resolution, contrast-enhanced, T1-weighted axial MR images were obtained for each patient on the day of the procedure. All tumor resections were performed under the guidance of a neuronavigation system [StealthStation Treon (Medtronic, Minneapolis, MN, USA) or Stryker (Stryker Instruments, Kalamazoo, MI, USA)] using the MR images. Additional functional MR images and diffusion tensor images were used as appropriate, depending on tumor location. Zeiss OPMI Pentero microscopes (Carl Zeiss Surgical GmbH, Oberkochen, Germany) equipped with BLUE 400 fluorescence technology, which enabled switching from conventional standard white xenon light to filtered violet-blue excitation light for visualization of fluorescence, were used in all patients. In all cases, the tumor was resected to the extent possible consistent with safety, and supratotal resection was performed in some patients with a tumor in a non-eloquent area. After the opening of lateral ventricles, the fluorescence of the ventricular wall was examined with a microscope by switching between white light and violet-blue excitation light. Regions were annotated as non-visible, weak, or strong fluorescence for 5-ALA-induced fluorescence by the operating neurosurgeon, and samples of these regions were collected for histopathological analysis. Before sampling, regions of ventricular walls were checked macroscopically for tumor involvement and confirmed with the aid of the neuronavigation system. Tumor involvement was defined as the presence of macroscopic invasion of tumor or enhancement on the preoperative contrast-enhanced T1-weighted MR images used for neuronavigation.

Histopathological analysis. Specimens from patients with GBM were freshly obtained from the operating room. Samples of ventricular walls for histopathological analysis were categorized according to the presence or absence of 5-ALA-induced fluorescence by the operating neurosurgeon and were forwarded to the neuropathology department. Histopathological analyses were performed on hematoxylin and eosin (H\&E)-stained, formalin-fixed, paraffin-embedded tissues from the main tumor mass and ventricular wall. Immunohistochemical staining for glial fibrillary acidic protein (GFAP), the proliferation marker Ki-67, epidermal growth factor receptor (EGFR), and p53 was also carried out to establish a definitive diagnosis. $\mathrm{O}^{6}$-methylguanine DNA methyltransferase (MGMT) promoter methylation status and isocitrate dehydrogenase 1 (IDH1) mutations were analyzed by polymerase chain reaction (PCR), and loss of heterozygosity (LOH) at chromosomes $1 \mathrm{p}$ and $19 \mathrm{q}$ was determined by fluorescent in situ hybridization. One experienced neuropathologist diagnosed the type and grade of each sample based on the World Health Organization (WHO) 2007 grading criteria (21). To reduce bias, the neuropathologist was blinded to the 5-ALA fluorescence status. Samples in which tumor cells could not be identified and where increased levels of proliferation were not detectable were considered tumor-free.

\section{Results}

Ventricle wall fluorescence and sample collection. In each case, the tumor was clearly revealed in the surgical field and exhibited 5-ALA-induced fluorescence under blue light. Seventeen cases showed strong fluorescence of the main tumors and 2 cases showed weak fluorescence of the main tumors. 5-ALA-induced fluorescence in the ventricular wall was identified in 11 patients (57.9\%) after opening the lateral ventricle. The fluorescent areas of the ventricular wall varied from one case to another. In these 11 patients, 5 showed strong fluorescence of the ventricular walls and 6 showed weak fluorescence of the ventricular walls. However, there was no correlation between the fluorescence intensity of the ventricular wall and that of the main tumors. A total of 25 samples of the ventricular wall, which is divided into 5 regions (anterior horn, body, atrium, occipital horn, and temporal horn) along the rostrocaudal axis (22), were collected intraoperatively from the 19 GBM patients: five from the anterior horn, one from the atrium, 2 from the occipital horn, and 12 from the temporal horn. Of these 25 samples, 11 showed observable intraoperative 5-ALA-induced fluorescence, whereas 14 samples did 
Table I. Clinical and molecular characteristics of the 19 patients with glioblastoma multiforme.

\begin{tabular}{|c|c|c|c|c|c|c|c|c|c|c|}
\hline $\begin{array}{l}\text { Case } \\
\text { no. }\end{array}$ & $\begin{array}{l}\text { Age } \\
\text { (years), } \\
\text { gender }\end{array}$ & $\begin{array}{l}\text { Tumor } \\
\text { location }\end{array}$ & $\begin{array}{l}\text { Extent of } \\
\text { resection }\end{array}$ & $\begin{array}{c}\text { Tumor } \\
\text { contact to } \\
\text { lateral ventricle }\end{array}$ & $\begin{array}{c}\text { IDH1 } \\
\text { mutation }\end{array}$ & EGFR & $\begin{array}{c}\mathrm{p} 53 \\
\text { mutation } \\
(\%)\end{array}$ & $\begin{array}{c}\mathrm{Ki}-67 \\
\mathrm{LI} \\
(\%)\end{array}$ & $\begin{array}{c}\text { MGMT } \\
\text { promoter } \\
\text { methylation }\end{array}$ & $\begin{array}{l}1 \mathrm{p} \mathrm{LOH} / \\
19 \mathrm{q} \mathrm{LOH}\end{array}$ \\
\hline 1 & $61, \mathrm{M}$ & Rt. FT & Subtotal & Yes & No & $2+$ & 40 & 60 & Unmethylated & No/Yes \\
\hline 2 & $66, \mathrm{~F}$ & Rt. TP & Total & Yes & No & $3+$ & 3 & 50 & Unmethylated & Yes/Yes \\
\hline 3 & $61, \mathrm{M}$ & Rt. temporal & Total & Yes & No & $3+$ & 5 & 20 & Unmethylated & Yes/No \\
\hline 4 & $70, \mathrm{~F}$ & Rt. TPO & Subtotal & Yes & No & $3+$ & Negative & 30 & Methylated & $\mathrm{No} / \mathrm{No}$ \\
\hline 5 & $62, \mathrm{~F}$ & Rt. frontal & Supratotal & No & No & $3+$ & Negative & 5 & Methylated & $\mathrm{No} / \mathrm{No}$ \\
\hline 6 & $53, \mathrm{M}$ & Lt. temporal & Total & Yes & No & $3+$ & 2 & 60 & Unmethylated & $\mathrm{No} / \mathrm{No}$ \\
\hline 7 & $45, \mathrm{M}$ & Rt. frontal & Total & Yes & No & $3+$ & Negative & 50 & Methylated & Yes/No \\
\hline 8 & $45, \mathrm{M}$ & Rt. TPO & Subtotal & No & No & $3+$ & 30 & 40 & Unmethylated & $\mathrm{No} / \mathrm{No}$ \\
\hline 9 & $58, \mathrm{~F}$ & Lt. TP & Total & Yes & No & $2+$ & 60 & 30 & Methylated & Yes/Yes \\
\hline 10 & $56, \mathrm{M}$ & Rt. temporal & Supratotal & Yes & No & $1+$ & 2 & 5 & Methylated & $\mathrm{No} / \mathrm{No}$ \\
\hline 11 & $51, \mathrm{M}$ & Lt. FT & Subtotal & Yes & No & $2+$ & 40 & 15 & Unmethylated & $\mathrm{No} / \mathrm{No}$ \\
\hline 12 & $51, \mathrm{M}$ & Lt. frontal & Total & Yes & Yes & 0 & 25 & 7 & Methylated & Yes/Yes \\
\hline 13 & $62, \mathrm{~F}$ & Rt. temporal & Subtotal & Yes & No & $1+$ & 5 & 20 & Unmethylated & $\mathrm{No} / \mathrm{No}$ \\
\hline 14 & $58, \mathrm{~F}$ & Lt. TP & Total & Yes & No & $3+$ & Negative & 3 & Unmethylated & $\mathrm{No} / \mathrm{No}$ \\
\hline 15 & $67, \mathrm{M}$ & Rt. TPO & Subtotal & Yes & No & $3+$ & 90 & 40 & Methylated & Yes/Yes \\
\hline 16 & $74, \mathrm{M}$ & Lt. temporal & Subtotal & Yes & No & $1+$ & 70 & 30 & Unmethylated & $\mathrm{No} / \mathrm{No}$ \\
\hline 17 & $65, \mathrm{~F}$ & Rt. temporal & Total & No & No & 0 & 1 & 3 & Unmethylated & $\mathrm{No} / \mathrm{No}$ \\
\hline 18 & 46, M & Rt. temporal & Total & No & No & $3+$ & 5 & 20 & Unmethylated & $\mathrm{No} / \mathrm{No}$ \\
\hline 19 & $60, \mathrm{M}$ & Rt. PO & Supratotal & Yes & No & $3+$ & 20 & 25 & Unmethylated & $\mathrm{No} / \mathrm{No}$ \\
\hline
\end{tabular}

FT, frontotemporal; TP, temporoparietal; TPO, temporo-parieto-occipital; PO, parieto-occipital; LOH, loss of heterozygosity; LI, labeling index.

not (Table II). In all cases, the ventricular wall areas sampled showed no macroscopic evidence for tumor involvement and were free of enhancement on MR images.

Histopathological analysis of ventricular wall samples. Histopathological assessments of the main tumor mass confirmed WHO Grade IV GBM in every case (Fig. 1). Eleven ventricular wall samples with observable intraoperative 5-ALA-induced fluorescence were analyzed; 5 (45.5\%) were positive for the presence of tumor cells, whereas the remaining $6(54.5 \%)$ were free of tumor cells. Of the 5 ventricular wall samples that showed the presence of tumor cells, $2(40 \%)$ corresponded to low-grade glioma, and $3(60 \%)$ corresponded to high-grade glioma. Fourteen ventricular wall samples without observable intraoperative 5-ALA-induced fluorescence were analyzed; no tumor cells were identified in any of the 14 samples (Table II). 5-ALA exhibited a sensitivity of $100 \%$ and specificity of $70 \%$ [95\% confidential interval (CI): 45.72-88.11\%] in detecting tumor invasion of ventricular wall samples. Positive predictive values and negative predictive values were $45.5 \%$ (95\% CI: $16.75-76.62 \%$ ) and $100 \%$. The overall accuracy of this method was $76 \%$. However, we did not find any correlation between the fluorescence intensity and the pathological finding of the ventricular wall in this study.

\section{Illustrative cases}

Patient 1. A 62-year-old woman (case 13) presented with a 1-month history of headache and progressive left hemiparesis. Preoperative MR images revealed a right temporal enhancing

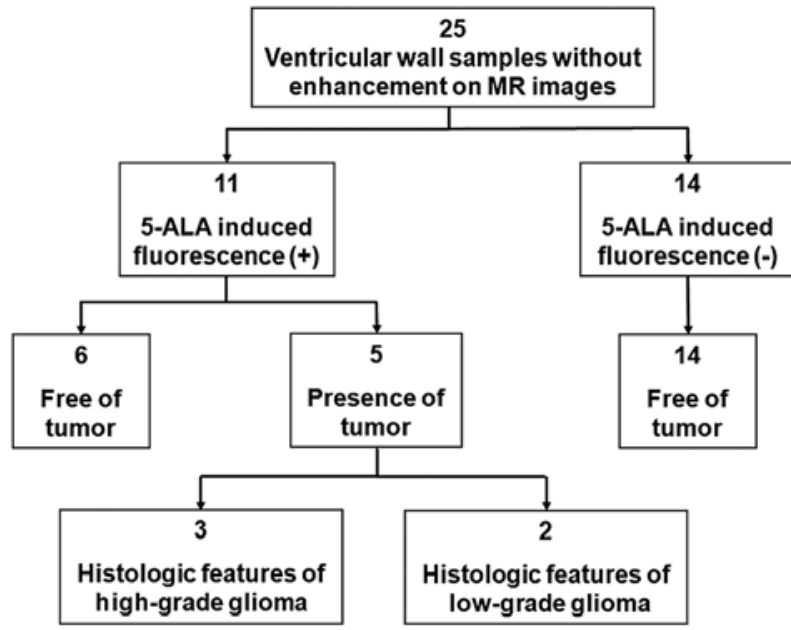

Figure 1. Summary of histopathological assessments of the ventricular wall samples.

mass extending to the frontal lobe and insula (Fig. 2A). A right fronto-temporal craniotomy was performed with 5-ALA fluorescence guidance and the tumor was subtotally removed with a temporal lobectomy. A histopathological analysis confirmed diagnosis of the main tumor mass as GBM. During resection of the tumor, we entered the temporal horn of the left lateral ventricle (Fig. 2B), and detected apparent fluorescence on some parts of the ventricular wall (Fig. 2C). Ventricular wall 
Table II. 5-ALA fluorescence characteristics and pathological findings of the 19 patients with glioblastoma multiforme.

\begin{tabular}{|c|c|c|c|c|c|}
\hline \multirow[b]{2}{*}{$\begin{array}{l}\text { Case } \\
\text { no. }\end{array}$} & \multirow[b]{2}{*}{$\begin{array}{l}\text { Ventricular wall } \\
\text { sampling site }\end{array}$} & \multirow{2}{*}{$\begin{array}{l}\text { 5-ALA } \\
\text { fluorescence } \\
\text { of tumor }\end{array}$} & \multicolumn{2}{|c|}{ Ventricular wall tissue } & \multirow[b]{2}{*}{$\begin{array}{l}\text { Presence of } \\
\text { tumor cells }\end{array}$} \\
\hline & & & $\begin{array}{l}\text { No. of } \\
\text { samples }\end{array}$ & $\begin{array}{c}\text { 5-ALA } \\
\text { fluorescence }\end{array}$ & \\
\hline 1 & Temporal horn & Strong & 1 & Strong & Yes (low-grade) \\
\hline 2 & Temporal horn & Strong & 1 & Strong & No \\
\hline 3 & Temporal horn & Strong & 2 & $\begin{array}{l}\text { Weak } \\
\text { Non-visible }\end{array}$ & $\begin{array}{c}\text { Yes (low-grade) } \\
\text { No }\end{array}$ \\
\hline 4 & Temporal horn & Strong & 2 & $\begin{array}{l}\text { Strong } \\
\text { Non-visible }\end{array}$ & $\begin{array}{c}\text { Yes (high-grade) } \\
\text { No }\end{array}$ \\
\hline 5 & Anterior horn & Strong & 1 & Non-visible & No \\
\hline 6 & Temporal horn & Strong & 2 & $\begin{array}{l}\text { Weak } \\
\text { Non-visible }\end{array}$ & $\begin{array}{l}\text { No } \\
\text { No }\end{array}$ \\
\hline 7 & Anterior horn & Weak & 1 & Non-visible & No \\
\hline 8 & Occipital horn & Strong & 1 & Weak & No \\
\hline 9 & Temporal horn & Weak & 1 & Non-visible & No \\
\hline 10 & Temporal horn & Strong & 2 & $\begin{array}{l}\text { Weak } \\
\text { Non-visible }\end{array}$ & $\begin{array}{l}\text { No } \\
\text { No }\end{array}$ \\
\hline 11 & Anterior horn & Strong & 1 & Non-visible & No \\
\hline 12 & Anterior horn & Strong & 1 & Non-visible & No \\
\hline 13 & Temporal horn & Strong & 2 & $\begin{array}{l}\text { Weak } \\
\text { Non-visible }\end{array}$ & $\begin{array}{c}\text { Yes (high-grade) } \\
\text { No }\end{array}$ \\
\hline 14 & Atrium & Strong & 1 & Strong & Yes (high-grade) \\
\hline 15 & Temporal horn & Strong & 2 & $\begin{array}{l}\text { Strong } \\
\text { Non-visible }\end{array}$ & $\begin{array}{l}\text { No } \\
\text { No }\end{array}$ \\
\hline 16 & Temporal horn & Strong & 1 & Non-visible & No \\
\hline 17 & Temporal horn & Strong & 1 & Non-visible & No \\
\hline 18 & Temporal horn & Strong & 1 & Non-visible & No \\
\hline 19 & Occipital horn & Strong & 1 & Weak & No \\
\hline
\end{tabular}

samples obtained as part of the planned temporal lobectomy were analyzed histopathologically. The presence of tumor consistent with high-grade glioma was confirmed in a sample of weakly fluorescent ventricular wall tissue without contrast enhancement on MR images (Fig. 2D). The pathological diagnosis of strongly fluorescent ventricular wall tissue with contrast enhancement on MR images was GBM (Fig. 2E). No tumor cells were identified in the sample from the non-fluorescent ventricular wall tissue lacking contrast enhancement on MR images (Fig. 2F). A postoperative MR image showed that the tumor was resected to the greatest possible extent, and an additional right temporal lobectomy was performed (Fig. 2G).

Patient 2. A 67-year-old man (case 15) presented with a 2-week history of confusion, left homonymous hemianopsia, and left hemiparesis. Preoperative MR images revealed a right temporo-parietal enhancing mass that involved the posterior part of the temporal horn of the right lateral ventricle (Fig. 3A and B). The tumor was resected under the guidance of 5-ALA fluorescence, and showed strong red fluorescence under blue light. The histopathological diag- nosis of the main tumor mass was GBM. After the ventricle was opened (Fig. 3C and D), we encountered fluorescence in the ventricle walls that were free of enhancement on MR images (Fig. 3E and F). Ventricular wall samples obtained as part of the planned lesionectomy and temporal lobectomy were analyzed histopathologically. The pathological diagnosis of strongly fluorescent ventricular wall tissue with contrast enhancement on MR images was GBM (Fig. 3G). No tumor cells were identified in the samples from either strongly fluorescent ventricular wall tissue or non-fluorescent ventricular wall tissue lacking contrast enhancement on MR images (Fig. 3H and I). A postoperative MR image showed that the tumor was resected to the extent possible, and an additional right temporal lobectomy was performed (Fig. 3J and K).

\section{Discussion}

Because 5-ALA has been widely used for improving surgery of malignant gliomas, it is not rare to detect 5-ALA-induced fluorescence of the ventricle wall in cases where the ventricle is 


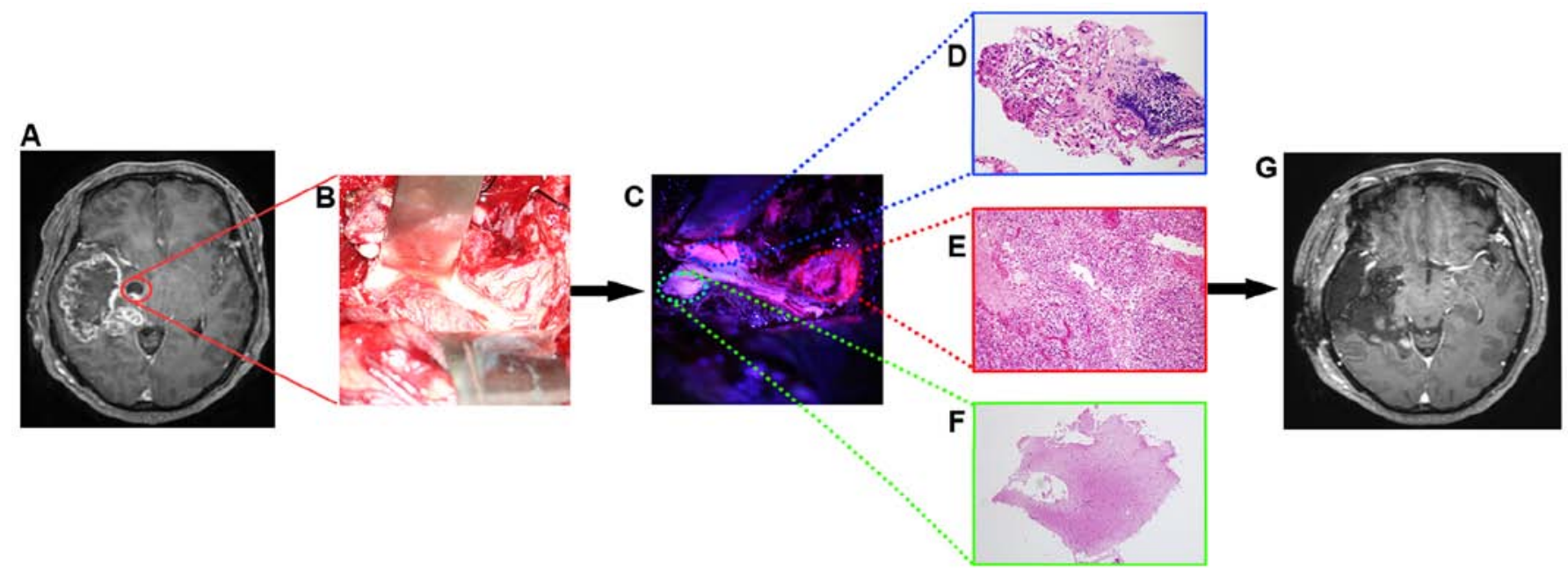

Figure 2. Case 13. (A) Preoperative, axial, T1-weighted, post-contrast MR image showing a tumor located near the lateral ventricle. (B) Intraoperative microscopic image under white light illumination showing the exposed temporal horn of the lateral ventricle. (C) Intraoperative microscopic image under blue light showing ventricular walls with varying intensity of fluorescence and no fluorescence. (D) Histopathological analysis of weakly fluorescent ventricular wall tissue lacking contrast enhancement on MR images, confirming the presence of a tumor consistent with high-grade glioma. (E) Histopathological analysis of strongly fluorescent ventricular wall tissue exhibiting contrast enhancement on MR images, confirming the presence of a tumor consistent with GBM. (F) Histopathological analysis of non-fluorescent ventricular wall tissue lacking contrast enhancement on MR images, confirming the absence of tumor (G) Axial T1-weighted post-contrast MR image showing a tumor resection that includes ventricular wall tissues as part of the planned margin of resection.
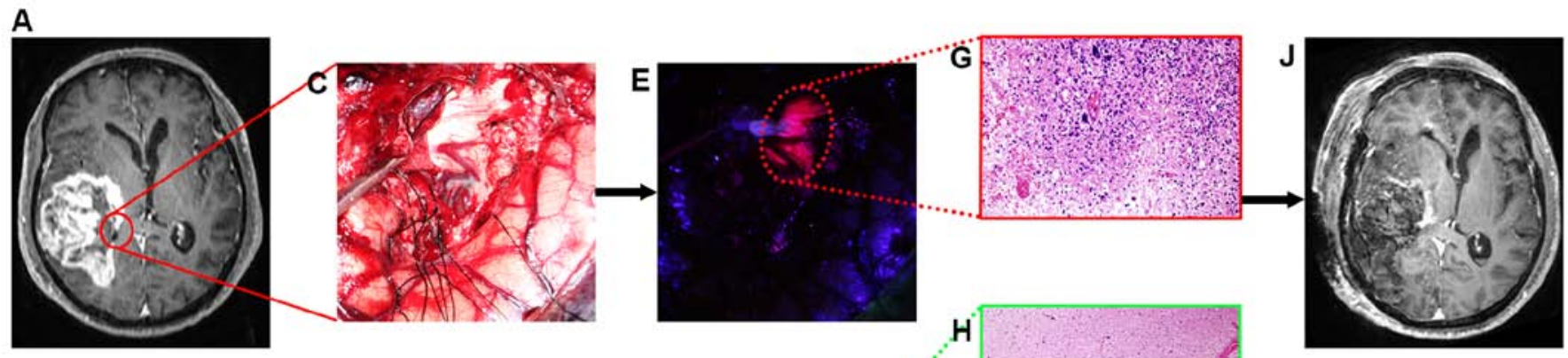

B
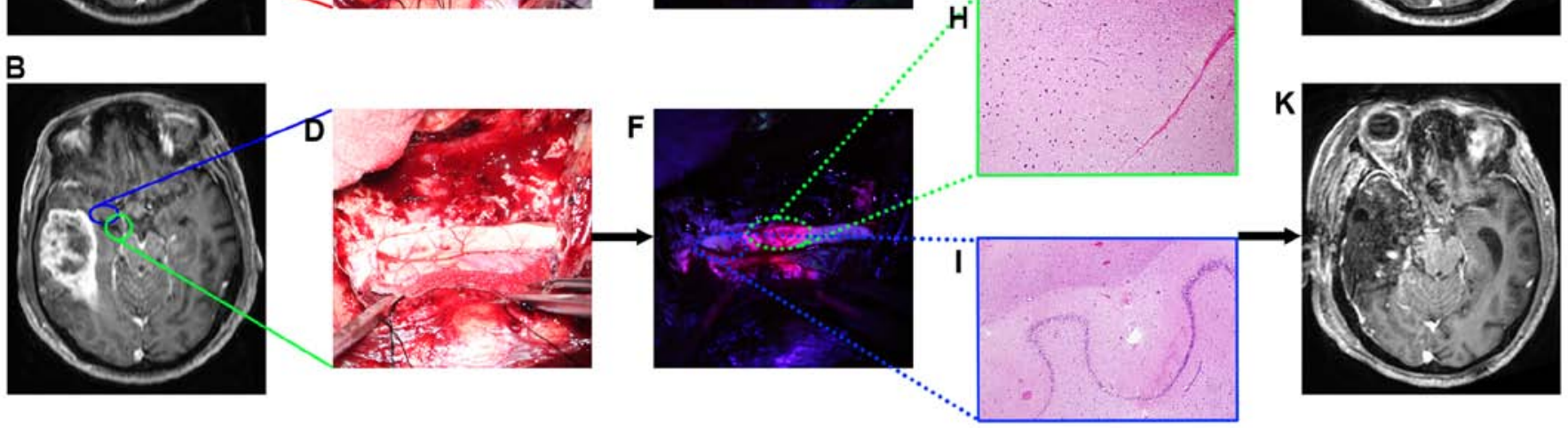

Figure 3. Case 15. (A) Preoperative, axial, T1-weighted, post-contrast MR image showing tumor involvement in the lateral ventricle. (B) Preoperative axial T1-weighted post-contrast MR image showing a temporal horn of the lateral ventricle without tumor involvement. (C) Intraoperative microscopic image under white light illumination showing the exposed lateral ventricle. (D) Intraoperative microscopic image under white light illumination showing the exposed temporal horn of the lateral ventricle. (E) Intraoperative microscopic image under blue light showing ventricular walls with strong fluorescence. (F) Intraoperative microscopic image under blue light showing ventricular walls with and without fluorescence. (G) Histopathological analysis of strongly fluorescent ventricular wall tissue exhibiting contrast enhancement on MR images, confirming the presence of a tumor consistent with GBM. (H) Histopathological analysis of strongly fluorescent ventricular wall tissue lacking contrast enhancement on MR images, confirming the absence of tumor. (I) Histopathological analysis of non-fluorescent ventricular wall tissue lacking contrast enhancement on MR images, confirming the absence of tumor. (J) Axial, T1-weighted, post-contrast MR image demonstrating resection of a tumor. (K) Axial T1-weighted post-contrast MR image showing a tumor resection that includes ventricular wall tissues as part of the planned margin of resection.

opened during the operation $(23,24)$. Although the relationships between 5-ALA-induced fluorescence and pathologic parameters in gliomas and peritumoral tissues have been extensively investigated, few studies have addressed the histopathological implications of 5-ALA-induced fluorescence in ventricular wall tissues that show no tumor involvement. In a series of 7 patients with periventricular GBMs, Hayashi et al (23) found that most ventricle wall tissues with unenhanced MR images that showed 5-ALA-induced fluorescence were positive for the presence of tumor cells, whereas all tissues showed disrup- 
tion of ependymal cell layers of the ventricle wall. On the basis of this study, these authors suggested that tumor cells in the ventricular wall or environmental changes around the ventricle could lead to 5-ALA fluorescence of the ventricular wall. In a separate study, Tejada-Solís et al (24) concluded that ventricular wall fluorescence does not always indicate glioma cell invasion of the ventricular wall, based on the observation that 3 out of $8(37.5 \%)$ cases that underwent selective biopsy of fluorescent ventricle wall exhibited an intact ependymal layer and no tumor cells. However, these studies were limited by the small number of cases and the lack of negative control specimens.

In the present study, we compared pathological findings of fluorescent ventricular walls with those of non-fluorescent ventricular walls using a relatively large number of samples in a homogeneous group of patients. To maintain the homogeneity of the patient population, we only included patients with newly diagnosed GBM. To eliminate the possibility of pseudo-positive 5-ALA-induced fluorescence in ventricular wall samples, we excluded patients diagnosed with recurring GBM that had undergone prior treatment, including surgery and radiotherapy, because areas showing infiltration of inflammatory cells associated with surgical and radiation interventions can also accumulate PpIX and show 5-ALA-induced fluorescence $(25,26)$.

Compared with the previous studies described above, we obtained a relatively large number of samples from various domains of the lateral ventricle, including non-fluorescent ventricular wall samples as a negative control group. Most of the ventricular wall samples were excised during surgery as part of the planned margin of resection surrounding the GBM. Maximizing the extent of resection likely extends time to progression and increases survival, and supratotal resection of gliomas in non-eloquent regions can be beneficial for clinical outcomes $(10,14,15,27-29)$. Accordingly, we tried to increase the extent of resection during neurosurgical procedures. Because we sought to achieve supratotal resection and additional lobectomy if possible during the removal of GBMs in non-eloquent areas, most ventricular wall samples were consequently included in the resected area. Therefore, we could safely harvest samples from ventricular walls. Additionally, for safety we collected intraoperative samples from ventricular walls in accordance with certain a prior criteria. First, we did not intentionally open the ventricle during the surgical procedure to check for fluorescence in the ventricular wall or to obtain ventricular wall samples. Because ventricular opening during surgical procedures can be a risk factor for postoperative hydrocephalus and leptomeningeal dissemination, which may potentially worsen the clinical condition and decrease survival (30-35), opening of the ventricular system was performed only in cases where it was needed for radical supratotal resection of the tumor. Second, ventricular wall samples in the safe area were collected carefully to prevent postoperative neurological sequelae. Functionally important areas, including the fornix, were excluded from ventricular wall sampling, because neurological sequelae can occur due to direct damage to the area. We also excluded certain areas with vascular structures, such as internal cerebral veins and thalamostriate veins, to prevent ischemic insult. Third, we tried to obtain a sufficient ventricular wall sample to clearly assess histopathology, while limiting the depth of tissue resection to $<5 \mathrm{~mm}$ to prevent damage to structures under the surface.

In our series, ventricular wall fluorescence was detected in a majority (57.9\%) of patients, but not in all patients. Considering the variety of locations in the lateral ventricle that showed fluorescence, the frequency of existence of ventricular wall fluorescence may be underestimated since we did not explore the entire lateral ventricle. Five of the 11 (45.5\%) fluorescent ventricular wall samples contained glioma cells, whereas none of the 14 non-fluorescent samples showed infiltration of tumor cells (Fig. 1). In contrast to previous studies of the relationships between 5-ALA fluorescence and the pathology of tissue in GBM $(9,36,37)$, the low positive predictive values (PPVs) and high negative predictive values (NPVs) in our series indicate that non-fluorescent ventricular walls under blue light should lack invading tumor cells. On the other hand, fluorescent ventricular walls could possibly reflect the presence of tumor cells, even though the fluorescence is not always related to the infiltration of tumor cells into the ventricular wall. Because the NPV depends greatly on the non-fluorescent tissue biopsy algorithm, the high NPV in our series may imply that ventricular wall samples remote from the tumor and not invaded by tumor cells were properly collected. The likelihood of not finding tumor cells should be higher if sampling sites are remote from the tumor than would be the case if they are close to the tumor. Our results suggest that, in cases where the ventricular wall is fluorescent, there is a chance of tumor cell infiltration into the ependymal spaces; accordingly, we recommend close follow-up with imaging studies and monitoring of the patient's clinical status after the surgical resection of GBM if 5-ALA-induced fluorescence of the ventricular wall is detected during surgery. Since fluorescence can be an indication of ependymal glioma cell invasion or leptomeningeal seeding in some cases, a biopsy should be performed to decide treatment options if feasibility and safety allow. However, postoperative radiotherapy covering the whole ventricle system based on the presence of ventricular wall fluorescence should be avoided because it may not always indicate pathological glioma cell invasion.

Six of the ventricular wall samples in our series were falsely fluorescing, showing no evidence of the presence of tumor cells. This raises questions regarding the meaning of false-positive fluorescence in the ventricular wall. False-positive fluorescence previously described by others was related to infiltration of inflammatory cells and reactive astrocytes, necrosis, prominent vasculature, or peritumoral edema $(26,36,37)$. However, we did not observe such findings in our false-positive ventricular wall samples and found no difference between falsely fluorescing ventricular wall samples and non-fluorescent control samples from the standpoint of histopathology. The intraoperative 5-ALA-induced fluorescence in the 2 samples corresponding to low-grade glioma might be a false-positive finding because the vast majority of low-grade gliomas do not exhibit visible intraoperative fluorescence under a surgical microscope (38-40). A better understanding of 5-ALA-induced fluorescence in the ventricular wall will require further investigation, including a molecular characterization, of these falsely fluorescing samples. In a study with GBM patients by Piccirillo et al (41), the histologic analysis and genomic characterization revealed that the fluorescent subependymal zone contained tumor-initiating 
cells, however most samples from the fluorescent subependymal zone were truly fluorescing as they were included in the contrast enhancing lesion on MR images and pathologically confirmed to be involved by tumor. Studies with samples from 5-ALA-induced fluorescent ventricular wall tissues which show no tumor involvement are still lacking.

One limitation of this study is its subjective assessment of intraoperative 5-ALA-induced ventricular wall fluorescence. We adopted a trinary approach - non-visible, weak, or strong fluorescence - to assess fluorescence. However, this approach is subjective as fluorescence was estimated by a surgeon using only a surgical microscope with a specific filter. Overcoming this limitation would require quantitative or semiquantitative fluorescence measurements capable of objectively discriminating fluorescence intensity. These modalities, such as intraoperative spectrometry or confocal microscopy, have proven to be more sensitive for the determination of 5-ALA-induced fluorescence than the surgical microscope used here, although these modalities for quantitative determination of fluorescence still need to be validated for clinical use $(37-39,42,43)$. Another limitation of this study is that infiltration of the tumor was judged based on enhancement on T1-weighted, contrast-enhanced MR images. GBMs have an infiltrative nature, and their presence is not always associated with a disrupted BBB; thus, contrast enhancement may not show invasive areas of GBM because it only depicts areas with a disruption in the BBB. Accordingly, active tumor tissue can exist beyond the area of contrast enhancement. T2-weighted and fluid-attenuated inversion recovery MR images may depict invasive areas of GBM; however, it is difficult to determine the extent of the non-enhancing component of the tumor using these approaches owing to peritumoral edema $(44,45)$. On this account, there is the possibility of tumor invasion into ventricular wall samples in some cases, despite the fact that we obtained ventricular wall samples that were definitely remote from the enhanced lesion in MR images. Errors in the neuronavigation system related to image-to-patient registration error and intraoperative brain shift are also a limitation of this study. In all cases, the ventricle was opened and a considerable amount of cerebrospinal fluid was drained out during the surgery, which might subsequently degrade navigational accuracy over the course of a surgical procedure. We tried to compensate for such errors using intracranial anatomical landmarks; however, this method is subjective and could not eliminate the error completely.

In summary, our data suggest the possibility that glioma cells are present in ventricle walls exhibiting 5-ALA fluorescence despite the absence of tumor involvement in MR images. Ventricular walls lacking 5-ALA fluorescence and enhancement on MR images may be free of tumor, so a decision to resect non-fluorescent ventricular walls should be made carefully. Further investigations of non-tumor cells from tissues exhibiting 5-ALA fluorescence are needed to understand the nature of ventricular wall fluorescence.

\section{Acknowledgements}

This study was supported by grants from the Basic Science Research Program through the National Research Foundation of Korea (NRF) funded by the Ministry of Education, Science and Technology (NRF-2013R1A1A2055597), and the Korean
Health Technology R\&D Project, Ministry of Health \& Welfare, Republic of Korea (HI13C1509).

\section{References}

1. Friesen SA, Hjortland GO, Madsen SJ, Hirschberg H, Engebraten O, Nesland JM and Peng Q: 5-Aminolevulinic acid-based photodynamic detection and therapy of brain tumors (Review). Int J Oncol 21: 577-582, 2002.

2. Regula J, MacRobert AJ, Gorchein A, Buonaccorsi GA, Thorpe SM, Spencer GM, Hatfield AR and Bown SG: Photosensitisation and photodynamic therapy of oesophageal, duodenal, and colorectal tumours using 5 aminolaevulinic acid induced protoporphyrin IX - a pilot study. Gut 36: 67-75, 1995.

3. Ohgari Y, Nakayasu Y, Kitajima S, Sawamoto M, Mori H, Shimokawa O, Matsui $\mathrm{H}$ and Taketani S: Mechanisms involved in delta-aminolevulinic acid (ALA)-induced photosensitivity of tumor cells: Relation of ferrochelatase and uptake of ALA to the accumulation of protoporphyrin. Biochem Pharmacol 71: 42-49, 2005.

4. Teng L, Nakada M, Zhao SG, Endo Y, Furuyama N, Nambu E, Pyko IV, Hayashi Y and Hamada JI: Silencing of ferrochelatase enhances 5-aminolevulinic acid-based fluorescence and photodynamic therapy efficacy. Br J Cancer 104: 798-807, 2011.

5. Valdés PA, Moses ZB, Kim A, Belden CJ, Wilson BC, Paulsen KD, Roberts DW and Harris BT: Gadolinium- and 5 -aminolevulinic acid-induced protoporphyrin IX levels in human gliomas: An ex vivo quantitative study to correlate protoporphyrin IX levels and blood-brain barrier breakdown. J Neuropathol Exp Neurol 71: 806-813, 2012.

6. Ennis SR, Novotny A, Xiang J, Shakui P, Masada T, Stummer W, Smith DE and Keep RF: Transport of 5-aminolevulinic acid between blood and brain. Brain Res 959: 226-234, 2003.

7. Stummer W, Stepp H, Möller G, Ehrhardt A, Leonhard M and Reulen HJ: Technical principles for protoporphyrin-IX-fluorescence guided microsurgical resection of malignant glioma tissue. Acta Neurochir (Wien) 140: 995-1000, 1998.

8. Stummer W, Stocker S, Wagner S, Stepp H, Fritsch C, Goetz C, Goetz AE, Kiefmann R and Reulen HJ: Intraoperative detection of malignant gliomas by 5 -aminolevulinic acid-induced porphyrin fluorescence. Neurosurgery 42: 518-525; discussion 525-516, 1998.

9. Zhao S, Wu J, Wang C, Liu H, Dong X, Shi C, Shi C, Liu Y, Teng L, Han D, et al: Intraoperative fluorescence-guided resection of high-grade malignant gliomas using 5-aminolevulinic acid-induced porphyrins: A systematic review and meta-analysis of prospective studies. PLoS One 8: e63682, 2013.

10. Chaichana KL, Cabrera-Aldana EE, Jusue-Torres I, Wijesekera O, Olivi A, Rahman M and Quinones-Hinojosa A: When gross total resection of a glioblastoma is possible, how much resection should be achieved? World Neurosurg 82: e257-e265, 2014.

11. Lacroix M, Abi-Said D, Fourney DR, Gokaslan ZL, Shi W, DeMonte F, Lang FF, McCutcheon IE, Hassenbusch SJ, Holland E, et al: A multivariate analysis of 416 patients with glioblastoma multiforme: Prognosis, extent of resection, and survival. J Neurosurg 95: 190-198, 2001.

12. McGirt MJ, Chaichana KL, Gathinji M, Attenello FJ, Than K, Olivi A, Weingart JD, Brem $\mathrm{H}$ and Quiñones-Hinojosa AR: Independent association of extent of resection with survival in patients with malignant brain astrocytoma. J Neurosurg 110: 156-162, 2009

13. Pichlmeier U, Bink A, Schackert G, Stummer W; ALA Glioma Study Group: Resection and survival in glioblastoma multiforme: An RTOG recursive partitioning analysis of ALA study patients. Neuro Oncol 10: 1025-1034, 2008.

14. Sanai N, Polley MY, McDermott MW, Parsa AT and Berger MS: An extent of resection threshold for newly diagnosed glioblastomas. J Neurosurg 115: 3-8, 2011.

15. Stummer W, Reulen HJ, Meinel T, Pichlmeier U, Schumacher W, Tonn JC, Rohde V, Oppel F, Turowski B, Woiciechowsky C, et al; ALA-Glioma Study Group: Extent of resection and survival in glioblastoma multiforme: Identification of and adjustment for bias. Neurosurgery 62: 564-576, discussion 564-576, 2008.

16. Stummer W, Pichlmeier U, Meinel T, Wiestler OD, Zanella F and Reulen HJ; ALA-Glioma Study Group: Fluorescence-guided surgery with 5-aminolevulinic acid for resection of malignant glioma: A randomised controlled multicentre phase III trial. Lancet Oncol 7: 392-401, 2006. 
17. Willems PW, Taphoorn MJ, Burger H, Berkelbach van der Sprenkel JW and Tulleken CA: Effectiveness of neuronavigation in resecting solitary intracerebral contrast-enhancing tumors: A randomized controlled trial. J Neurosurg 104: 360-368, 2006.

18. Senft C, Bink A, Franz K, Vatter H, Gasser T and Seifert V: Intraoperative MRI guidance and extent of resection in glioma surgery: A randomised, controlled trial. Lancet Oncol 12: 997-1003, 2011.

19. Unsgaard G, Selbekk T, Brostrup Müller T, Ommedal S, Torp SH, Myhr G, Bang J and Nagelhus Hernes TA: Ability of navigated 3D ultrasound to delineate gliomas and metastases - comparison of image interpretations with histopathology. Acta Neurochir (Wien) 147: 1259-1269, discussion 1269, 2005.

20. De Witt Hamer PC, Robles SG, Zwinderman AH, Duffau H and Berger MS: Impact of intraoperative stimulation brain mapping on glioma surgery outcome: A meta-analysis. J Clin Oncol 30: 2559-2565, 2012.

21. Louis DN, Ohgaki H, Wiestler OD, Cavenee WK, Burger PC, Jouvet A, Scheithauer BW and Kleihues P: The 2007 WHO classification of tumours of the central nervous system. Acta Neuropathol 114: 97-109, 2007.

22. Rhoton AL Jr: The lateral and third ventricles. Neurosurgery 51 (Suppl): S207-S271, 2002.

23. Hayashi Y, Nakada M, Tanaka S, Uchiyama N, Hayashi Y, Kita D and Hamada J: Implication of 5-aminolevulinic acid fluorescence of the ventricular wall for postoperative communicating hydrocephalus associated with cerebrospinal fluid dissemination in patients with glioblastoma multiforme: A report of 7 cases. J Neurosurg 112: 1015-1019, 2010.

24. Tejada-Solís S, Aldave-Orzaiz G, Pay-Valverde E, MarigilSánchez M, Idoate-Gastearena MA and Diez-Valle R: Prognostic value of ventricular wall fluorescence during 5-aminolevulinic-guided surgery for glioblastoma. Acta Neurochir (Wien) 154: 1997-2002; discussion 2002, 2012.

25. Miyatake S, Kuroiwa T, Kajimoto Y, Miyashita M, Tanaka H and Tsuji M: Fluorescence of non-neoplastic, magnetic resonance imaging-enhancing tissue by 5 -aminolevulinic acid: Case report Neurosurgery 61: E1101-E1103; discussion E1103-E1104, 2007.

26. Utsuki S, Oka H, Sato S, Shimizu S, Suzuki S, Tanizaki Y, Kondo K, Miyajima Y and Fujii K: Histological examination of false positive tissue resection using 5-aminolevulinic acid-induced fluorescence guidance. Neurol Med Chir (Tokyo) 47: 210-213, discussion 213-214, 2007.

27. Duffau H: Is supratotal resection of glioblastoma in noneloquent areas possible? World Neurosurg 82: e101-e103, 2014

28. Grabowski MM, Recinos PF, Nowacki AS, Schroeder JL, Angelov L, Barnett GH and Vogelbaum MA: Residual tumor volume versus extent of resection: Predictors of survival after surgery for glioblastoma. J Neurosurg 121: 1115-1123, 2014.

29. Wolbers JG: Novel strategies in glioblastoma surgery aim at safe, supra-maximum resection in conjunction with local therapies. Chin J Cancer 33: 8-15, 2014

30. Bae JS, Yang SH, Yoon WS, Kang SG, Hong YK and Jeun SS The clinical features of spinal leptomeningeal dissemination from malignant gliomas. J Korean Neurosurg Soc 49: 334-338, 2011.

31. Fischer CM, Neidert MC, Péus D, Ulrich NH, Regli L, Krayenbühl N and Woernle CM: Hydrocephalus after resection and adjuvant radiochemotherapy in patients with glioblastoma. Clin Neurol Neurosurg 120: 27-31, 2014.

32. Montano N, D'Alessandris QG, Bianchi F, Lauretti L, Doglietto F, Fernandez E, Maira G and Pallini R: Communicating hydrocephalus following surgery and adjuvant radiochemotherapy for glioblastoma. J Neurosurg 115: 1126-1130, 2011.
33. Saito R, Kumabe T, Jokura H, Shirane R and Yoshimoto T: Symptomatic spinal dissemination of malignant astrocytoma. J Neurooncol 61: 227-235, 2003.

34. Vertosick FT Jr and Selker RG: Brain stem and spinal metastases of supratentorial glioblastoma multiforme: A clinical series. Neurosurgery 27: 516-521; discussion 521-512, 1990.

35. Grabb PA, Albright AL and Pang D: Dissemination of supratentorial malignant gliomas via the cerebrospinal fluid in children. Neurosurgery 30: 64-71, 1992.

36. Roberts DW, Valdés PA, Harris BT, Fontaine KM, Hartov A, Fan X, Ji S, Lollis SS, Pogue BW, Leblond F, et al: Coregistered fluorescence-enhanced tumor resection of malignant glioma: Relationships between $\delta$-aminolevulinic acid-induced protoporphyrin IX fluorescence, magnetic resonance imaging enhancement, and neuropathological parameters. Clinical article. J Neurosurg 114: 595-603, 2011.

37. Stummer W, Tonn JC, Goetz C, Ullrich W, Stepp H, Bink A, Pietsch T and Pichlmeier U: 5-Aminolevulinic acid-derived tumor fluorescence: The diagnostic accuracy of visible fluorescence qualities as corroborated by spectrometry and histology and postoperative imaging. Neurosurgery 74: 310-319, discussion 319-320, 2014.

38. Sanai N, Snyder LA, Honea NJ, Coons SW, Eschbacher JM, Smith KA and Spetzler RF: Intraoperative confocal microscopy in the visualization of 5-aminolevulinic acid fluorescence in low-grade gliomas. J Neurosurg 115: 740-748, 2011.

39. Utsuki S, Oka H, Sato S, Suzuki S, Shimizu S, Tanaka S and Fujii K: Possibility of using laser spectroscopy for the intraoperative detection of nonfluorescing brain tumors and the boundaries of brain tumor infiltrates. Technical note. J Neurosurg 104: 618-620, 2006.

40. Widhalm G, Kiesel B, Woehrer A, Traub-Weidinger T, Preusser M, Marosi C, Prayer D, Hainfellner JA, Knosp E and Wolfsberger S: 5-Aminolevulinic acid induced fluorescence is a powerful intraoperative marker for precise histopathological grading of gliomas with non-significant contrast-enhancement. PLoS One 8: e76988, 2013.

41. Piccirillo SG, Spiteri I, Sottoriva A, Touloumis A, Ber S, Price SJ, Hey wood R, Francis NJ, Howarth KD, Collins VP, et al: Contributions to drug resistance in glioblastoma derived from malignant cells in the sub-ependymal zone. Cancer Res 75: 194-202, 2015.

42. Valdés PA, Kim A, Brantsch M, Niu C, Moses ZB, Tosteson TD, Wilson BC, Paulsen KD, Roberts DW and Harris BT: $\delta$-aminolevulinic acid-induced protoporphyrin IX concentration correlates with histopathologic markers of malignancy in human gliomas: The need for quantitative fluorescence-guided resection to identify regions of increasing malignancy. Neuro-oncol 13: 846-856, 2011 .

43. Valdés PA, Leblond F, Kim A, Harris BT, Wilson BC, Fan X, Tosteson TD, Hartov A, Ji S, Erkmen K, et al: Quantitative fluorescence in intracranial tumor: Implications for ALA-induced PpIX as an intraoperative biomarker. J Neurosurg 115: 11-17, 2011.

44. Wen PY, Macdonald DR, Reardon DA, Cloughesy TF, Sorensen AG, Galanis E, Degroot J, Wick W, Gilbert MR, Lassman AB, et al: Updated response assessment criteria for high-grade gliomas: Response assessment in neuro-oncology working group. J Clin Oncol 28: 1963-1972, 2010.

45. Cage TA, Pekmezci M, Prados M and Berger MS: Subependymal spread of recurrent glioblastoma detected with the intraoperative use of 5-aminolevulinic acid: Case report. J Neurosurg 118: $1220-1223,2013$ 